\title{
AN APPROACH TO THE STUDY OF TRANSVERSE
}

\section{MIXING IN STREAMS}

Laszlo Somlyódy

International Institute for Applied Systems Analysis, Laxenburg, Austria

RR-82-44

December 1982

Reprinted from Journal of Hydraulic Research, volume 20 number 2 (1982)

INTERNATIONAL INSTITUTE FOR APPLIED SYSTEMS ANALYSIS

Laxenburg, Austria 
Research Reports, which record research conducted at IIASA, are independently reviewed before publication. However, the views and opinions they express are not necessarily those of the Institute or the National Member Organizations that support it.

Reproduced with permission from the Journal of Hydraulic Research 20(2):203-220.

Copyright (c) 1982 by International Association for Hydraulic Research, Delft, The Netherlands.

All rights reserved. No part of this publication may be reproduced or transmitted in any form or by any means, electronic or mechanical, including photocopy, recording, or any information storage or retrieval system, without permission in writing from the copyright holder. 


\section{FOREWORD}

The mixing of pollutants in rivers, lakes, and reservoirs because of turbulence and spatial non-uniformities in the velocity field considerably influences the fate of these materials. Mixing is an important factor when controlling water quality independently, whether it be a question of the deoxygenation, thermal pollution, contamination by heavy metals, or eutrophication - issues that have been central research themes of the Resources and Environment Area at IIASA over the past few years. This article considers transverse mixing in rivers, a phenomenon of great importance for wide rivers. A new approach is presented and tested on the basis of a wide range of experiments, from laboratory flumes to large natural rivers such as the Danube.

JANUSZ KINDLER

Chairman

Resources and Environment Area 


\title{
AN APPROACH TO THE STUDY OF TRANSVERSE MIXING IN STREAMS
}

\section{UNE APPROCHE DE L'ETUDE DU MELANGE TRANSVERSAL DANS LES COURANTS}

\author{
by/par
}

\section{SOMLYÓDY}

Research Centre for Water Resources Development, Budapest, Hungary, at present International Institute for Applied Systems Analysis, Austria

Summary Transverse mixing under steady conditions is studied by introducing the mass streamline as the streamline of the mass density vector field. The two equations derived for it allow calculations of the concentration field, or the dispersion coefficient under different assumptions if the concentrations are given. The correctness of numerical methods developed was tested. Tracer studies have been performed on five different streams $\left(Q=0.25-2000 \mathrm{~m}^{3} \mathrm{~s}^{-1}\right)$ and data published have also been used. The methods based on the concept of mass streamline were applied, and the results were compared to observed concentrations. The limitations of the two-dimensional treatment have been examined finally. Key words: streams, channels, hydraulics, diffusion, dispersion, turbulence, water, water pollution, numerical methods.

Résumé Le mélange transversal en régime permanent est étudié en introduisant les lignes de courant de masse définies comme les lignes de courant du champ du vecteur densité de masse. Les deux équations qui s'en déduisent permettent les calculs du champ de concentration, ou du coefficient de dispersion, sous différentes hypothèses, dans le cas où les concentrations sont connues. L'exactitude des méthodes numériques employées a été vérifiée. Des études avec traceur ont été effectuées avec cinq courants différents $\left(\mathrm{Q}=0,25-2000 \mathrm{~m}^{3} \mathrm{~s}^{-1}\right)$ et des données publiées ont également été utilisées. Les méthodes utilisant le concept de ligne de courant de masse ont été appliquées et les résultats ont été comparés aux concentrations observées. Enfin les limitations de la résolution du problème à deux dimensions ont été examinées. Mots clés: courants, canaux, hydrauliques, diffusion, dispersion, turbulence, eau, pollution de l'eau, méthodes numériques.

\section{Introduction}

An understanding of the concentration distribution of pollutants discharged into the recipients, in other words of the mixing process, is of paramount importance in solving pollution control problems in site selection of effluent discharges and water diversions, in designing fresh-water-cooled power stations, as well as in planning a water quality observation network. Under the conditions that the velocity field and diffusion coefficients are known, furthermore that the effluent is discharged with the same velocity and density as in the ambient water, the process is described by the equation of turbulent diffusion. Additional simplifications are made in the majority of problems by the main feature of river geometry (width $>$ depth), as a result of which uniformity over depth occurs usually within a short distance, the phenomena being thus reduced to one of transverse mixing. In most of the cases steady flow and pollutant release can be also assumed. All these assumptions allow description of the mixing process by the two-dimensional, steady-state equation of turbulent dispersion as it was done by Holley [4], Yctsukara and Sayre [20] and others.

As demonstrated by Sayre and Chang [12] the effect of longitudinal dispersion is negligible in this case. By various considerations the equation itself can be transformed to a modified form more readily adapted to the stream characteristics and the data

Received April 14, 1981

Journal of Hydraulic Research 20 (1982) No. 2 

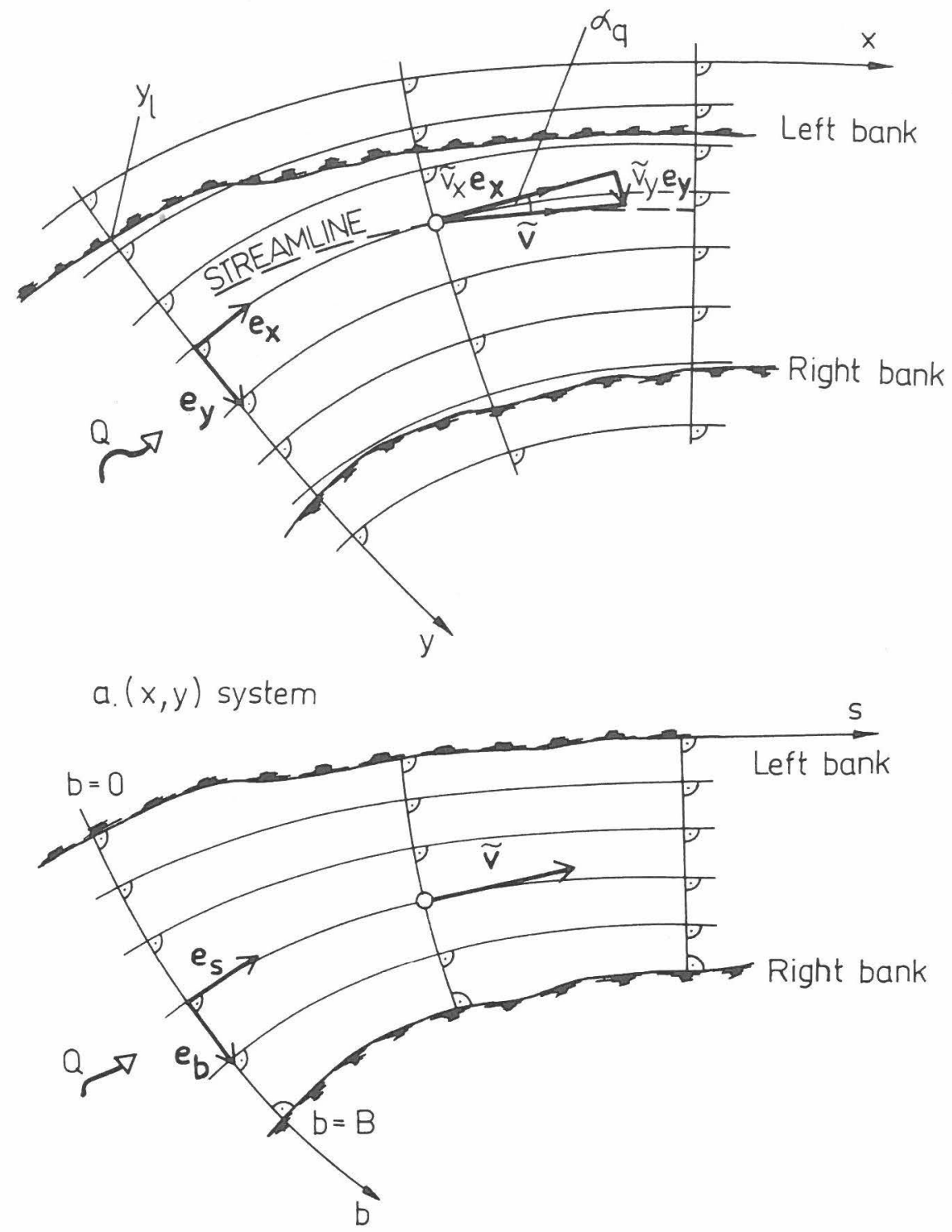

b. $(s, b)$ system

Orthogonal curvilinear coordinate systems
Fig. 1

. 1 Systèmes de coordonnées en repère
curviligne orthogonal 
available, and easier to solve numerically for determining the concentration field. These have prompted Fischer to introduce the stream tube concept [3], [11], [19], Yotsukara and Cobb [18] the cumulative discharge, Chang [2], Yotsukara and Sayre [20], further Somlyódy [13] the orthogonal, curvilinear system of coordinates following the bend conditions. Further modification was suggested by Somlyódy [15] upon introducing the stream-lines of the mass density vector field, the concept and equations of the mass streamline.

The coefficient of transverse mixing involved in the governing equation is in general inaccessible to theoretical determination, since it reflects the effects of both turbulence and non-uniformities over depth, and is found in the majority of cases by tracer measurements. Systematical experiments have provided the means for studying the dispersion coefficient in correlation with the principal hydraulic and geometric variables. In this respect the works of Bansal [1], Paal et al. [10], Krishnappen and Lau [7], Lau and Krishnappen [8], further of Muszkalay [9] are to be mentioned.

The estimation of the dispersion coefficient from a known concentration field may be termed an inverse problem, the solution of which becomes necessary after the completion of tracer measurements. Here the development of a method of sufficiently general validity is considered desirable. The perhaps most frequently adopted approach is the change of moment method generalized by Holley [4], [5].

\section{Objective}

The aims of the present paper are i) to derive the equations of the mass streamline and to present the main characteristics thereof, ii) to develop numerical methods for solving the two problems mentioned before, iii) to apply these methods on artificial and natural streams of different size and character, finally iv) to investigate the limitations of the two-dimensional approach.

\section{Governing equations}

The equation of turbulent diffusion

Under the assumptions mentioned in the foregoing the continuity equation

$$
\operatorname{div}(\mathrm{h} \stackrel{\widetilde{J}}{)}=0
$$

related to the mass density vector $\widetilde{\widetilde{J}}=\widetilde{\mathrm{c} \underline{v}}$ can be written in a curvilinear, orthogonal system of coordinates $(x, y)$ following more-or-less closely the curvatures of the stream (Fig. 1) into the form

$$
\frac{\partial}{\partial x}\left(m_{y} \underline{\tilde{v}} \underset{x}{x} \tilde{\bar{c}}\right)+\frac{\partial}{\partial x}\left(m_{x} \underline{\tilde{h}} \underset{y}{\tilde{c}}\right)=\frac{\partial}{\partial y}\left(\frac{m_{x}}{m_{y}} h D_{y} \frac{\partial \overline{\bar{c}}}{\partial y}\right)
$$

This is the familiar, two-dimensional equation of turbulent dispersion (c.f. Yotsukara and Sayre [20]). Here $\mathrm{c}$ is concentration, $\mathrm{v}_{\mathrm{x}}$ and $\mathrm{v}_{\mathrm{y}}$ are the local velocity components, $D_{y}$ is the local dispersion coefficient, $h$ the local flow depth, while $m_{x}$ and $m_{y}$ are the metric coefficients. The overbar above a symbol indicates averaging over time, while the wave-line a depth integrated value. The overbar will be omitted subsequently, unless it is considered essential.

The $(\mathrm{s}, \mathrm{b})$ system consisting of the streamlines and the trajectories perpendicular thereto, of the vector field $\underline{\underline{v}}$ is defined hereafter (Fig. 1). The streamlines are 
described by two equations $\left(\widetilde{v}_{X} \neq 0\right.$, a $\left.q / \partial y \neq 0\right)$ :

$$
\frac{d y}{d x}=\frac{m_{x}}{m_{y}} \frac{\widetilde{v}_{y}}{\widetilde{v}_{x}}=\frac{m_{x}}{m_{y}} \tan \alpha_{q}
$$

and

$$
\frac{d y}{d x}=\frac{\partial q / \partial x}{\partial q / \partial y}=-\frac{1}{m_{y} h \widetilde{v}_{x}} \frac{\partial}{\partial x} \int_{y_{1}}^{y} m_{y} h \widetilde{v}_{x} d y^{\prime}
$$

indicating that i) the vector $\underline{\widetilde{v}}$ is at every point the tangent of the streamline and ii) the change in the cumulative discharge $\mathrm{q}=\int_{\mathrm{y}}^{\mathrm{s}} \quad \mathrm{m}_{\mathrm{y}} \mathrm{C} \widetilde{\mathrm{v}}_{\mathrm{X}} \mathrm{dy}$ ' along the streamline is zero. In this system of coordinates the $\mathrm{y}_{1}$ transverse convective term is logically eliminated and Eq. (2) assumes the form

$$
\frac{\partial}{\partial s}\left(m_{b} h \widetilde{v}_{S} \widetilde{c}\right)=\frac{\partial}{\partial b}\left(\frac{m_{s}}{m_{b}} h D_{b} \frac{\partial \widetilde{c}}{\partial b}\right) \text {. }
$$

An additional advantage is that the boundary condition (zero mass transfer) along the bankline is simpler to formulate.

The mass stramline and the equations thereof

Considering the formal similarity between the continuity equation of flow $\operatorname{div}(\mathrm{h} \underline{\mathrm{v}})=0$ and Eq. (1) it appears logical to trace the streamlines of the vector field $\widetilde{J}$ (these will be termed mass streamlines) and the expressions thereof corresponding to Eqs. (3) and (4). Adopting a similar approach (Fig. 2) the first equation of the mass streamline becomes $\left(\widetilde{\jmath}_{\mathrm{X}} \neq 0\right)$ :

$$
\frac{\mathrm{dy}}{\mathrm{dx}}=\frac{\mathrm{m}_{\mathrm{x}}}{\mathrm{m}_{\mathrm{y}}} \frac{\tilde{\mathrm{J}}_{\mathrm{y}}}{\widetilde{\mathrm{J}}_{\mathrm{x}}}=\frac{\mathrm{m}_{\mathrm{x}}}{\mathrm{m}_{\mathrm{y}}} \tan \alpha
$$

where $\widetilde{J}_{x} \cong \widetilde{v}_{x} \widetilde{c} ; \quad \widetilde{J}_{y}=\widetilde{v}_{y} \tilde{c}-\frac{1}{m_{y}} D_{y} \frac{\partial c}{\partial y}$.

In terms of the latter the tangent of the angle is given as

$$
\tan \alpha=\frac{\widetilde{v}_{y}}{\widetilde{v}_{x}}-\frac{D_{y}}{m_{y} \widetilde{v}_{x} \widetilde{c}} \frac{\partial \widetilde{c}}{\partial y}=\tan \alpha_{q}-\frac{D_{y}}{m_{y} \widetilde{v}_{x} \widetilde{c}} \frac{\partial \widetilde{c}}{\partial y}
$$

The second equation, just as the condition $\mathrm{dq}=0$ is an expression of the fact that the mass transport perpendicular to the streamline (averaged over time and depth) is zero:

$$
\stackrel{\circ}{m}=0
$$

where

$$
\stackrel{\circ}{\mathrm{m}}=\int_{\mathrm{y}_{1}}^{\mathrm{y}} \mathrm{m}_{\mathrm{y}} \mathrm{h} \widetilde{\mathrm{v}}_{\mathrm{x}} \widetilde{\mathrm{c}} d \mathrm{y}^{\prime}
$$


in terms of which the second equation becomes $(\partial \stackrel{0}{\mathrm{~m}} / \partial \mathrm{y} \neq 0)$ :

$$
\frac{d y}{d x}=\frac{\partial m / \partial x}{\partial m^{0} / \partial y}=-\frac{1}{m_{y} h \widetilde{v}_{x} \widetilde{c}} \frac{\partial}{\partial x} \int_{y_{1}}^{y_{0}} m_{y} h \widetilde{v}_{x} \widetilde{c} d y^{\prime} .
$$

In this way we have succeeded in describing the mass streamline by two equations, which are suited to determining the concentration field and the mass streamlines simultaneously. The solution of the problem is thus equivalent to the solution of Eq. (2).

The difference between the two sets of streamlines is readily appreciated from Eq. (7) and Fig. 2. The angel $\alpha$ is composed of two parts, the first of which, $\alpha_{q}$ is the angle included by the vector $\mathrm{v}$ and the coordinate line, and is characteristic of the flow. The second, $\alpha_{m}$ is the spreading angle, which varies from point to point (it can be demonstrated to be always less than $90^{\circ}$ ) and is determined by the mixing process taking place in the flow.

In the $(\mathrm{s}, \mathrm{b})$ system of coordinates $\tan \alpha_{\mathrm{q}}=0$ and the expressions assume the following simplified forms:

$$
\begin{aligned}
& \tan \alpha_{m}=-\frac{D_{b}}{m_{b} \widetilde{v}_{S} \widetilde{c}} \frac{\partial \widetilde{c}}{\partial b}=-\frac{D_{b}}{m_{b} \widetilde{v}_{S}} \frac{\partial}{\partial b} \quad(1 n \widetilde{c}) \\
& \stackrel{o}{m}=\int_{0}^{b} m_{b} h \widetilde{v}_{S} \widetilde{c} d^{\prime} .
\end{aligned}
$$

Evidently, Eqs, (6) and (10) are modified accordingly and simplifications become possible also by introducing the cumulative discharge.

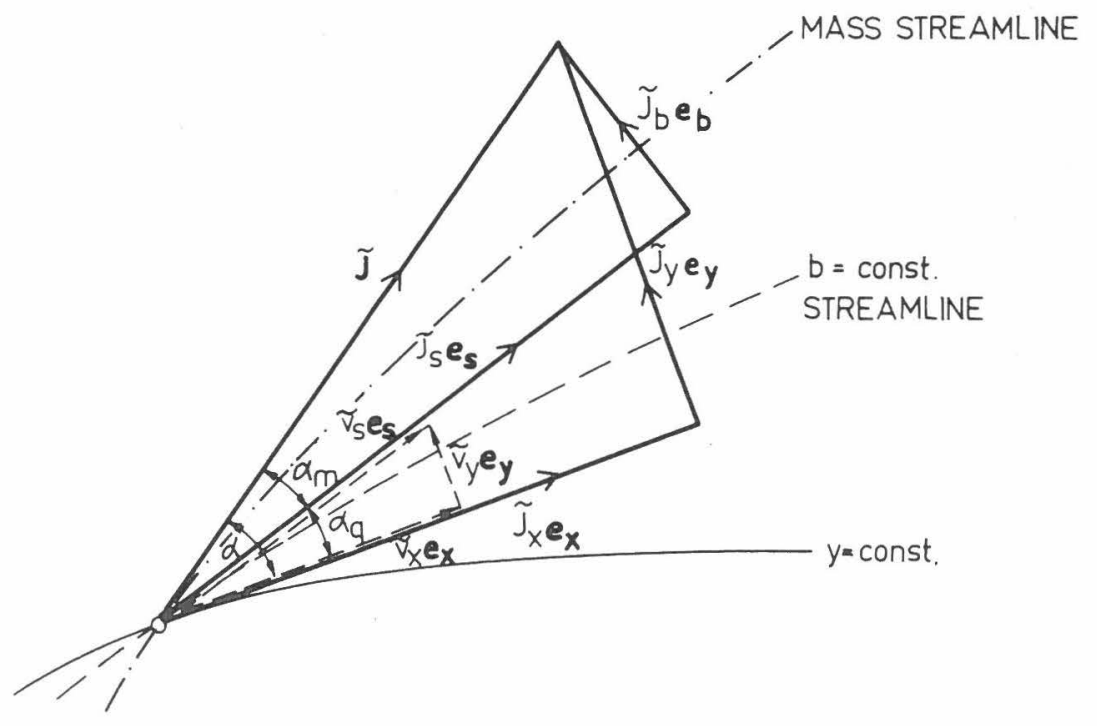

Definition sketch for the mass density vector in the $(x, y)$ and the $(s, b)$ co- $^{-}$ ordinate systems
Fig. 2 Schéma de définition du vecteur densité de masse dans les systèmes de coordonnées $(x, y)$ et $(s, b)$ 
Since at the banks no perpendicular mass transfer takes place, from Eq. (11)

$$
\tan \alpha_{m}(0)=\tan \alpha_{m}(B)=0
$$

follows, while on the upstream side of the river section $\widetilde{c}(o, b)$ and thus

$$
\tan \alpha_{m}(o, b)=f(b)
$$

is given.

Properties of the mass streamline and the mixing process

The tangent of the spreading angle $\alpha_{\mathrm{m}}$ according to Eq. (11) is proportionate to the product $\mathrm{D}_{\mathrm{b}} \partial \widetilde{\mathrm{c}} / \partial \mathrm{b}$.

The wider the angle $\alpha_{m}$, the more intensive is mixing. The contours of a plume starting from a pollution discharge (see e.g. Fig. 6) are bounded by mass streamlines. The extreme mass streamlines approach gradually the banks and even adhere to these, as expressed by Eq. (13). Hereafter the banks become not only streamlines, but also mass streamlines. Since the mass flux between two adjacent mass streamlines, thus in a mass flux tube remains always constant, the longitudinal change in concentration is due to a change in the flow rate within the mass flux tube (see later). Approaching uniform conditions $\partial \widetilde{c} / \partial b \rightarrow 0$, so that $\alpha_{m} \rightarrow 0$ and the mass streamlines tend to the streamlines.

\section{Computation of the concentration field and the mass streamline}

Solution scheme

Consider the curved edge of the river section examined assuming the $(\mathrm{s}, \mathrm{b})$ system of coordinates, as well as all quantities involved in the solution to be available as functions of $\mathrm{s}$ and $\mathrm{b}$. Using the method of finite differences the transverse trajectory $\mathrm{s}=0(\mathrm{j}=$ 0 ) has only been subdivided into equidistant discrete elements along the definition domain of the function $\widetilde{c}(0, b)$. The mass streamlines which emerge from the points indexed $i$ resulting in this way have been determined as described before. The concentration values have been obtained at the mid-points $k$ of the mass flux tubes formed by the adjacent mass streamlines. The longitudinal increment $\Delta s_{j}$ is not necessarily a constant one, it may be fixed in advance, or varied by steps on the basis of the stability condition (see later).

In general, the approximations to the mass streamlines are computed first between the trajectories $j$ and $(j+1)$ within the section $\Delta s_{j}$ (Fig. 3) with the help of Eq. (11). Here both an explicit and implicit scheme were developed based on three neighbour points and the previous one was found sufficiently accurate for practical purposes (this is of first order accuracy longitudinally and second order transversally). Once the $j$ and $(j+1) a p-$ proximations to the mass flux tubes have been determined, the term $\widetilde{c}_{k, j=l}$ is found from a simple mass balance expression [Fig. 3 and see also Eqs. (8), (10), and (12)]:

$$
\widetilde{c}_{k, j+l}=\frac{\Delta q_{k, j}}{\Delta q_{k, j+l}} \widetilde{c}_{k, j}
$$

The numerical scheme thus derived is conditionally stable having a similar condition as 


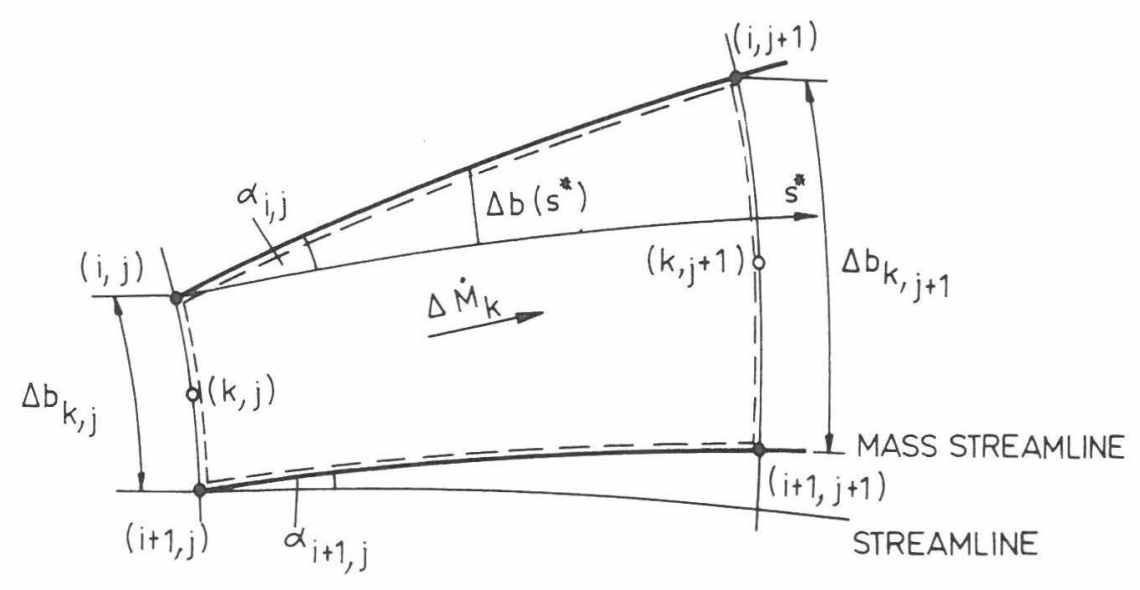

Derivation of the numerical solution

Fig. 3 Obtention de la solution numérique

the usual explicit central difference scheme for Eq. (5) (for details see [15]).

Boundary conditions

The boundary condition $\widetilde{\mathrm{c}}(0, \mathrm{~b})$ is assumed to be available from a near-field solution, or from measurement. Where this is not the case and a point source is considered, the condition $\widetilde{\mathrm{c}}(0, \mathrm{~b})$ can be obtained from an analytical solution of Eq. (5) for the immediate surroundings of the source.

Up to the point where the plume reaches the bank, the extreme mass streamlines are found by including the first, or last three computational points. After the water edge is reached, the boundary conditions are satisfied with the help of reflected points.

Main features of the numerical method

The common feature of the familiar difference methods is that the number of points at which the concentration is other than zero tends to increase together with the value of $\mathrm{j}$. Thus in the vicinity of a point source, where $\partial \widetilde{\mathrm{c}} / \partial \mathrm{b}$ is high, a few points are only considered, and then gradually more as the distribution becomes more uniform. Additionally, the edge of the plume depends greatly on the type of discretization adopted.

In the present method, as in the flow tube approach, the grid is in general non-uniform and the concentrations are obtained at the centers of the mass flux tubes. The number of points included in the calculation is equal along each $s=$ const. line. The results yields approximations of the mass streamline conforming to the physical particulars.

Detailed comparison between numerical and analytical solutions of Eq. (5) showed the appropriateness of the method outlined above [15].

Computer representation and data need

Two computer programmes were elaborated, one as a research tool while the other rather application oriented. The latter is based on geometrical data for cross-sections usually available in hydrologic data banks, a coupled model to compute the free surface profile and then $h(s, b)$ and different empirical relationships [for $D_{b}, \widetilde{v}_{S}(b)$ and the effect of bends]. 
The data need of the model is the same as e.g. that of the cumulative discharge method [20] and naturally the accuracy of model results essentially depends on the available knowledge of velocity distribution and dispersion coefficient for the river stretch considered (the application part of this paper involves some information in this respect). The required detailedness of geometric data depends on the uniformity of the river section studied, this is especially true if the pollutant is discharged in the near bank region.

\section{Solution of the inverse problem: calculation of $\mathrm{D}_{b}$}

The aim here is to find the unknown $D_{b}(s, b)$ coefficient by applying the equations presented before if the concentration field is known (mostly from tracer measurements).

As the first step the distribuations $\stackrel{\circ}{m}(\mathrm{~b})$ are determined in the cross-sections of

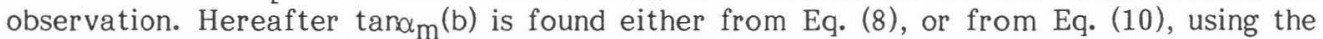
adjacent upstream and downstream cross-sections [see 14]. Two alternative ways can then be followed for determining $\mathrm{D}_{\mathrm{b}}$.

i) $D_{b}(s, b)=D_{b}(s)$. The first two terms of the series of Eqs. (11) are adopted as the starting basis. Both are multiplied by $h\left(b-b_{0}\right)$ and after rearrangement of terms the expression is integrated between the two edge $b_{i l}$ and $b_{r}$ of the plume. From the resulting expression $D_{b}(s)$ is obtained in the form

$$
D_{b}(s)=-\frac{1}{f(s)} \frac{1}{M} \int_{b_{l}}^{b_{r}} m_{s} h \widetilde{v}_{s} \tilde{c} \tan \alpha_{m}\left(b-b_{o}\right) d b .
$$

Here $b_{0}$ refers to an arbitrary coordinate line, $\stackrel{\circ}{M}=\stackrel{0}{m}\left(b_{r}\right)=\stackrel{0}{m}(B)$, while $f(s)$ is the same function as in the generalized change of moment equation [4], [15]:

$$
D_{b}=-\frac{1}{2 f(s)} \frac{d \sigma_{b}^{2}}{d s}
$$

which reflects also the correlation between the longitudinal change of the second moment $\alpha^{2}$ of the distribution $m_{b} h \widetilde{v}_{S} \widetilde{c}$ and the first moment of the distribution involved in Eq. (16).

ii) $\mathrm{D}_{\mathrm{b}}(\mathrm{s}, \mathrm{b})$. In this case the solution is obtained by numerical integration of Eq. (11) at $\mathrm{s}=$ const. Thus for instance, by applying the trapeze rule, the dispersion coefficient pertaining to the mid-points indexed $\mathrm{k}$ of the sections of width $\Delta \mathrm{b}=\left(\mathrm{b}_{\mathrm{r}}-\mathrm{b}_{1}\right) / \mathrm{N}$ is found from the expression

$$
D_{b_{k, j}}=\frac{\widetilde{v}_{S}\left(\tan \alpha_{m}\right)_{k, j}}{\ln \frac{\widetilde{c}_{i, j}}{\widetilde{c}_{i+1, j}}} \Delta b
$$

where $\Delta b$ denotes now the actual arch length, while i refers to the point of the mass streamline.

Among the two methods presented i) is essentially equivalent with the generalized change of the moment method. It is slightly more complicated but less sensitive on measurement and computational errors. Method ii) is more general but careful smoothing 


\section{Comparison of numerical and observation results}

To study the process of mixing and to illustrate the applicability of the methods developed, tracer measurements have been carried out on different streams comparing the numerical results with those observed. The results obtained by Holley [4] on the undistorted physical model of the IJssel river have also been included in the comparison. The investigations comprised thus the following cases:

\section{A. Laboratory studies}

A1. Open, straight rectangular flume in which the bottom roughness and injection point were varied $\left(\mathrm{Q}=0.05 \mathrm{~m}^{3} \mathrm{~s}^{-1}, \mathrm{~B}=1 \mathrm{~m}, \mathrm{H}=0.13 \div 0.15 \mathrm{~m}, \mathrm{~S}=1 \div 5.10^{-4}\right.$, length of measuring section $\mathrm{L}=12 \mathrm{~m}$ ).

A2. Model of a slightly curved section of the IJssel river. The channel is irregular (arrangement without groins). Injection at the centerline and at the side $(\mathrm{Q}=0.0141$ $\mathrm{m}^{3} \mathrm{~s}^{-1}, \mathrm{~B}=1.3-1.5 \mathrm{~m}, \mathrm{H}=0.08-0.09 \mathrm{~m}, \mathrm{~S}=6.10^{-5}, \mathrm{~L}=20 \mathrm{~m}$ ).

A3. Open, strongly curved rectangular flume with different injection points $(Q=$ $0.025^{3} \mathrm{~s}^{-1}, \mathrm{~B}=0.5 \mathrm{~m}, \mathrm{H}=0.14 \mathrm{~m}, \mathrm{R} / \mathrm{B}=1.71, \mathrm{~S}=10^{-3}, \mathrm{~L}=10 \mathrm{~m}$ ).

\section{B. Field observations}

B1. Kis-Rába, mildly curved, almost trapezoidal, lined irrigation canal, injection point close to the bankline $\left(\mathrm{Q}=8 \mathrm{~m}^{3} \mathrm{~s}^{-1}, \mathrm{~B}=8-11.5 \mathrm{~m}, \mathrm{H}=0.95-1.17 \mathrm{~m}, \mathrm{R} / \mathrm{B}=12-15\right.$, $\mathrm{S}=4 \cdot 1 \cdot 10^{-4}, \mathrm{~L}=250 \mathrm{~m}$ ).

B2. Danube stretch upstream of Budapest, between River Stations 1707 and $1660 \mathrm{~km}$ (investigations in two consecutive years at different sections, $Q=1000-2000 \mathrm{~m}^{3} \mathrm{~s}^{-1}$, $\left.\mathrm{B}=350-500 \mathrm{~m}, \mathrm{H}=3-5 \mathrm{~m}, \mathrm{~S}=6-8.10^{-5}\right)$.

B3. Rába river (tributary to the Danube). Meandering section, irregular channel, injection in the vicinity of the bank $\left(\mathrm{Q}=5.3 \mathrm{~m}^{3} \mathrm{~s}^{-1}, \mathrm{~B}=18-28 \mathrm{~m}, \mathrm{H}=0.4-1.3 \mathrm{~m}, \mathrm{R} / \mathrm{B}=5\right.$, $\left.\mathrm{S}=6 \cdot 10^{-4}\right)$.

The tracers used included dye solutions (Rhodamine B, methylene blue, Na-Fluoresceine) and occasionally a solution of sodium chloride. The tracer was injected as a point-, or vertical line source at a steady rate, virtually at the same velocity as that of the ambient flow.

The concentration was measured in most of the cases by discrete sampling at 7 to 10 verticals in each cross section and at 3-5 points in each vertical. The results were then averaged over depth, the values normalized in the knowledge of the tracer flux $M$ measured independently. Velocities were measured by means of different current meters depending on the size and character of the stream studied.

For evaluating the measurement data and for comparing them with the numerical results, the coefficient $D_{b}$ was always determined first, using Eqs. (16) - (18), then the concentration field employing the numerical method outlined before. This procedure differs from the simultaneous estimation of $\mathrm{D}_{\mathrm{b}}$ and $\widetilde{\mathrm{c}}$ often applied since it shows the correctness of the two independent methods. However, because the estimated $D_{b}$ is used in the second step of the analysis as input generally a good agreement should be expected between measured and computed concentrations.

A1. Open, straight, rectangular laboratory flume

The flume bottom consisted of sharp-edged gravel (12 $\mathrm{mm}$ mean size). The velocity distribution showed non-uniformities transversally probably due to the shortness of the inlet section. Owing also to this circumstance, the standard deviation of the longitudinal 
velocity increased in flow direction resulting in also a similar pattern in the dispersion coefficient. Dye measurements were performed by using central- and side injections. $D_{b}$ was calculated from Eqs. (16) and (17) alike, but the formation of $\mathrm{d \sigma}_{\mathrm{b}}{ }^{2} / \mathrm{ds}$ caused higher uncertainties in the latter case. For injection along the bank the $\mathrm{D}_{\mathrm{b}}$ values were consistently higher $\left(\mathrm{d}=\mathrm{D}_{\mathrm{b}} / \mathrm{Hu}^{*}\right.$ was 0.08 and 0.12$)$. Although $\mathrm{D}_{\mathrm{b}}(\mathrm{s})$ was not constant the measured concentration distributions were of Gaussuan character and the numerical calculations reflected them very well.

A2. The IJssel model

The arrangement of the model, the cross-sections of measurement, typical velocity- and depth distributions, further the computed plume contours pertaining to two different injection modes are shown in Fig. 4. The concentration distributions observed for injection at the bank are shown in Fig. 5 (see [4]). The evaluation has been based on the investigations of Holley, who has determined the dispersion coefficient among others under the assumptions $D_{b}(s, b)=$ const. and $D_{b}(s, b)=k h \widetilde{v}_{s}$, calculating therefrom the concentration field. The agreement between the calculated and observed values in the 10-15 cm wide range along the bank was unsatisfactory in each case, as illustrated also by the results shown for cross-section No. 2 in the figure. Holley has attributed this fact first of all to the transverse variations of $\mathrm{D}_{\mathrm{b}}$, the character of which is not described correctly by the expression $\mathrm{k} \mathrm{h} \widetilde{\mathrm{v}}_{\mathrm{S}}$ (see Fig. 5). Moreover, the results seem to imply non-conservative properties of the numerical method applied (Fig. 5).

In the present investigations $D_{b}(s, b)$ has been determined from Eq. (18), imposing no restriction whatsoever concerning the shape of $\mathrm{D}_{\mathrm{b}}(\mathrm{s}, \mathrm{b})$. The result for cross-section No. 2 has also been entered as an example in Fig. 5. The functions $D_{b}(b)$ obtained have hereafter resulted in very good agreement between the observed and calculated concentrations (Fig. 5).

B1. The Kis-Rába river

The experimental stretch, the point of injection and the mass streamlines calculated are shown in Fig. 6. The typical velocity- and depth distributions in the first few cross-sections are shown in Fig. 7. The tracer was injected as a point source and became uniform over depth within $50 \mathrm{~m}$. The concentration distributions obtained by measurement are shown in Fig. 8.

For the coefficient $D_{b}$ the value $0.011 \mathrm{~m}^{2} \mathrm{~s}^{-1}(\mathrm{~d} \cong 0.16$ ) has been obtained from Eqs. (16) and (17) alike, again with good agreement between the cbserved and calculated concentrations. The role of the velocity field should, however, be emphasized here. For instance, unless the distribution $\widetilde{v}_{\mathrm{S}}(\mathrm{b})$ in cross-section No. 1 is known (Fig. 7), it must be interpolated between the adjacent upstream and downstream cross-sections. As a consequence thereof, the approximations calculated will differ strongly from the observed values.

B2. The Danube

The experiment has been carried out upstream of Budapest, in the Vác Branch of the Danube, over a practically straight river stretch, in the vicinity of the right-hand bank. (For details see [14] - [16].) In the range of the plume, the calculated shape of which is shown in Fig. 9, the water depth ranged from 2-3 $\mathrm{m}$, the flow velocity from 0.65 to $0.80 \mathrm{~ms}^{-1}$, while the standard deviations of velocity from 0.04 to $0.09 \mathrm{~ms}^{-1}$. The tracer was injected as a point source at mid-depth, and became uniform over depth practically within $100 \mathrm{~m}$ distance. Concentrations were measured in six cross-sections situated within a distance of $800 \mathrm{~m}$ (Fig. 9). The dispersion coefficient found from Eq. (16) increased up to $600 \mathrm{~m}$, whereafter it diminished again [Fig. 9, $\mathrm{D}_{\mathrm{b}}(\mathrm{s})$ ], with $\mathrm{d} \cong 0.25$ corresponding to the mean value of $0.038 \mathrm{~m}^{2} \mathrm{~s}-1$.

The longitudinal variations of highest concentration are shown in Fig. 10. When using $D_{b}(s)$ the agreement between the observed and calculated values, as well as that of the transverse distributions (see [16]) is a very good one. The agreement is less satisfactory 


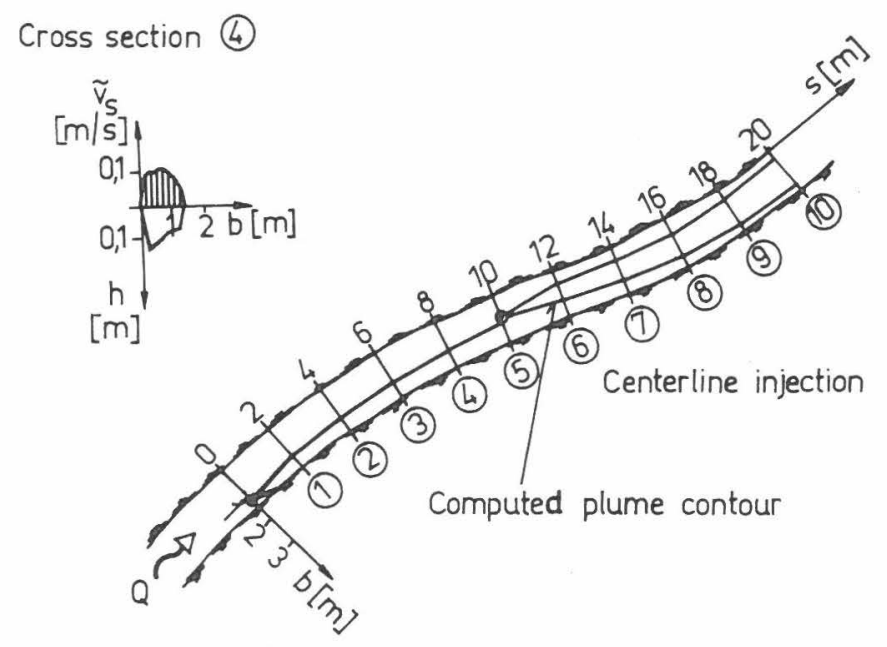

Side injection

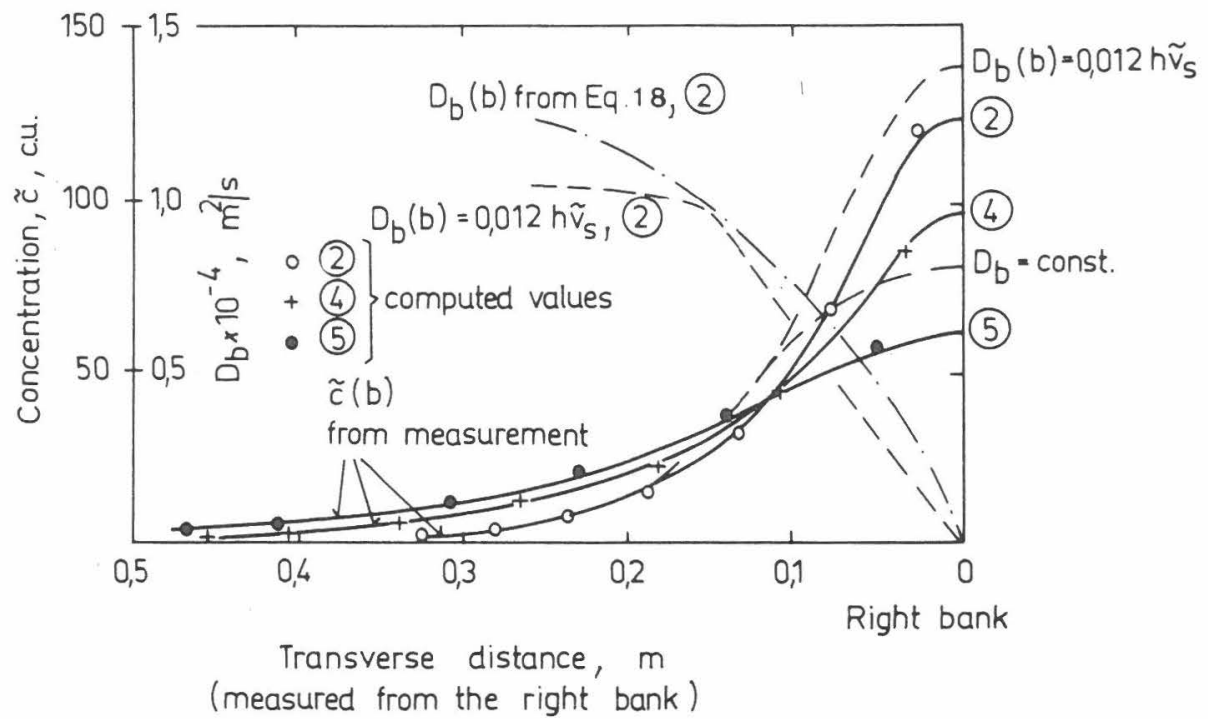

Comparison of measured and computed concentration. IJssel model, side injection (computed by Holley [4])
Fig. 5

Comparaison entre concentrations mesurées et calculées. Modèle IJssel injection latéral. (Calculs faits par Holley [4]) 


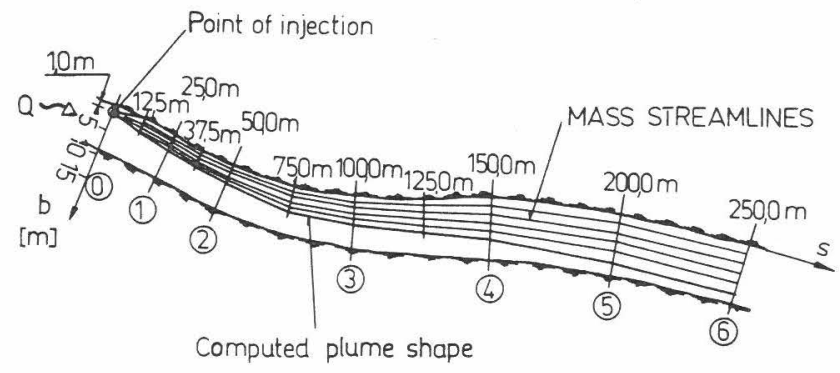

Examined stretch of the Kis-Rába River. The computer plume shape

Fig. 6 Schéma étudié pour la Kis-Rába. Le graphique en forme de plume calculé

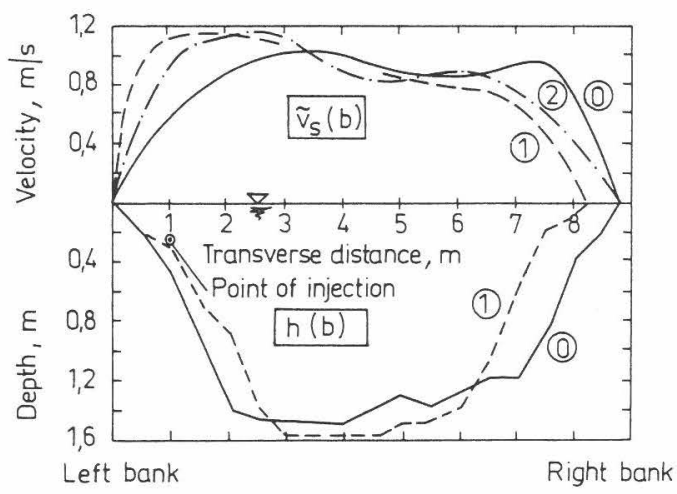

Kis-Rába River. Velocity and depth conditions

Fig. 7 Kis-Rába. Donnees sur les vitesses et profondeurs

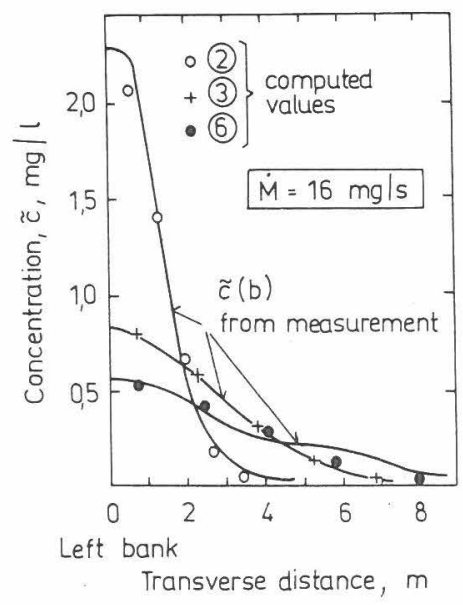

Comparison of observed and computed concentrations. Kis-Rába River
Fig. 8

Comparaison entre concentrations observées et calculées. Pour la Kis-Rába 


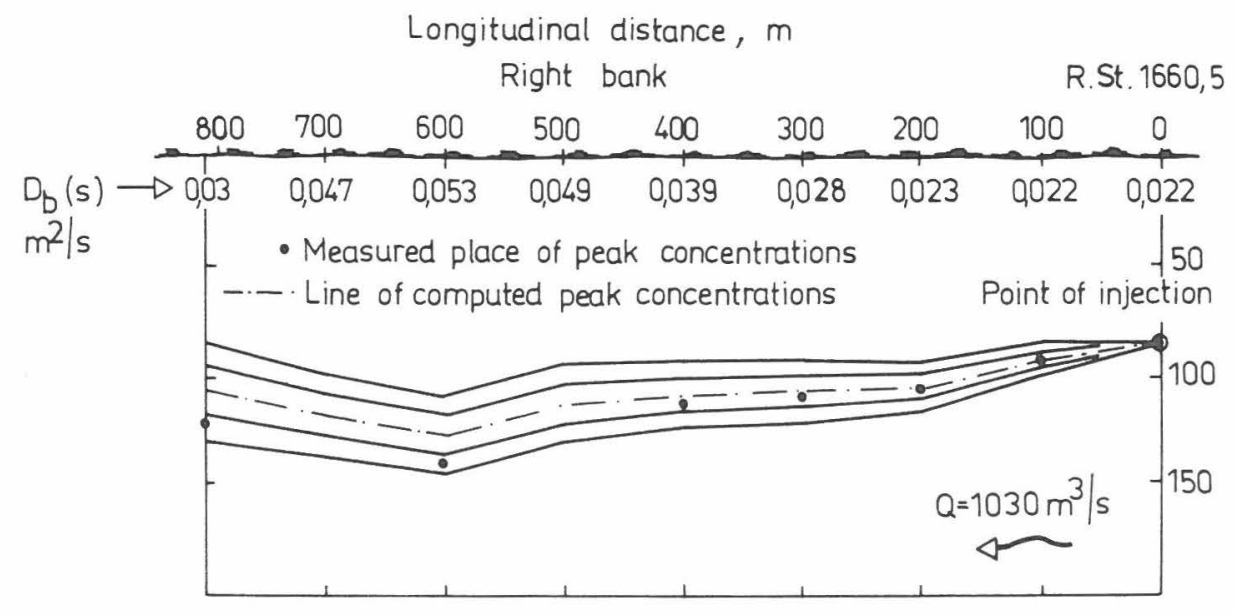
Computed plume shape. Danube River Fig. $9 \quad \begin{aligned} & \text { Graphique en forme de plume calculé. } \\ & \text { Pour le Danube }\end{aligned}$

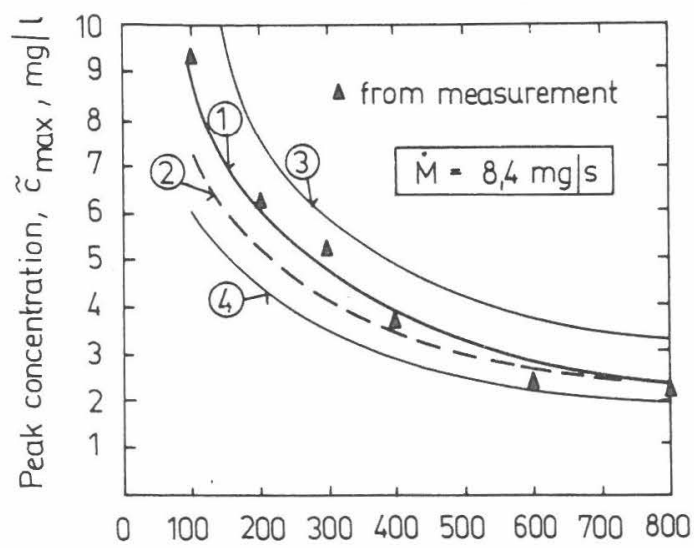

Point of injection

Longitudinal distance, $m$

Comparison of observed and computed concentrations. Danube River
Fig. 10

$$
\begin{array}{llll}
1 & D_{\mathrm{b}}=\mathrm{D}_{\mathrm{b}}(\mathrm{s}) & 2 & \mathrm{D}_{\mathrm{b}}=0.038 \mathrm{~m}^{2} / \mathrm{s} \\
3 & \mathrm{D}_{\mathrm{b}}=0.019 \mathrm{~m}^{2} / \mathrm{s} & 4 & \mathrm{D}_{\mathrm{b}}=0.057 \mathrm{~m}^{2} / \mathrm{s}
\end{array}
$$


when using the mean value of $D_{b}$ in the calculation (Fig. 10), and to illustrate the sensitivity of the solution the results pertaining to $\mathrm{D}_{\mathrm{b}}$ coefficients increased and reduced by 50 per cent have also been entered.

Evidently, the accuracy of the coordinates calculated is also of considerable importance, as illustrated in Fig. 9 by the points of peak concentration observed. These depart in the last two cross-sections from the calculated location, in that $\widetilde{c}_{\max }$ is observable along the central mass streamline practically over the entire length. The difference is due to the sudden change in the river bed around $500 \mathrm{~m}$ from the source round $100 \mathrm{~m}$ from the bank-line, the influence of which is not reflected truly by the streamlines calculated from the velocity distributions. (The error in direction is slightly less than 7 degrees.)

The application of the mixing model presented for a conservative material discharged by one of the tributaries, in combination with surface profile calculation over a round $60 \mathrm{~km}$ long stretch of the Danube has been described elsewhere [16]. The main conclusion of this study was that the dimensionless dispersion coefficient had to be increased as compared to the measurement results (approximately to $d=0.6$ ) to get a good agreement with observed concentrations. The reason lies in the fact that the length of the dye measurements (Fig. 9) was relatively short to the width of the river $(\sim 500 \mathrm{~m})$. Thus $\mathrm{D}_{\mathrm{b}}$ involved the contribution of non-uniformities along verticals in the region of the plume $(\sim 50 \mathrm{~m}$ width) only, but not over the whole cross section.

\section{Limitations to the two-dimensional approach The dispersion coefficient}

Consider first the series of equations defining the dispersion coefficient introduced after integration over depth:

$\frac{1}{h} \int_{0}^{h}\left(\overline{c^{\prime} v_{b}^{\prime}}+\bar{c}^{*} \bar{v}_{b}^{*}\right) d z=-\frac{1}{m_{b}} D_{b t} \frac{\partial \widetilde{c}}{\partial b}+\widetilde{c^{*}} \bar{v}_{b}^{*}=-\frac{1}{m_{b}}\left(D_{b t}+\Delta D_{b}\right) \frac{\partial \widetilde{c}}{\partial b}=-\frac{1}{m_{b}} \quad D_{b} \frac{\partial \widetilde{c}}{\partial b}(19$

in which the asterisk denotes the measured deviations from the depth-integrated value. The first terms reflect the effect of turbulence, the second terms that of non-uniformities in the vertical. Both, and thus their sum, have been described by a Fick type law $\left(D_{b}=D_{b t}+\Delta D_{b}\right)$.

Two different limiting factors will be considered subsequently, which result i) from the difficulties associated with the determination of the coefficients involved in the governing equation and ii) from the three-dimensional character of the phenomenon.

i) Let us examine a case where the introduction of a gradient-type transport is justified $\left(D_{b t}>0, \Delta D_{b} \geq 0\right)$. This is usually the case in alluvial channels if $R / B>5$, and in the absence of sudden contractions or expansions. Under such conditions the correctness of the solution depends on the accuracy of $\widetilde{v}_{S}(s, b)$ and $D_{b}(s, b)$. The influence of the former was illustrated by examples B1. and B2., whereas that of the latter by A2. and B2. Also, A2. demonstrated the sensitivity of the solution to variations of $D_{b}$ in the vicinity of the bank, where $\widetilde{v}_{S}$ and $h$ are also subjected to pronounced variations. For this reason $\widetilde{v}_{\mathrm{S}}(\mathrm{s}, \mathrm{b})$ and $\mathrm{D}_{\mathrm{b}}(\mathrm{s}, \mathrm{b})$ should be estimated carefully in practice. Field measurements are however usually prohibitively expensive. The derivation of velocities for stream bands from calculated surface profiles (see Holly [6]) is often unsatisfactory, while mean values for $\mathrm{D}_{\mathrm{b}}$ can at the most be assumed instead of $\mathrm{D}_{\mathrm{b}}(\mathrm{s}, \mathrm{b})$. As a consequence, no more than limited accuracy could be expected from the solution, so that interest has been concentrated on an overall description of mixing, on the determination of the principal characteristics (plume width, the average concentration related thereto, the mixing 
length, sensitivity, etc.).

ii) The second limitation results from the assumption under Eq. (19), and from the indtroduction of the concept of dispersion. The mathematical problem is substantially simplified thereby, but it is usually impossible to verify their validity. The transport a* ${ }^{*}$ reflecting to three-dimensional effects may be of a kind differing from assumed one, amplifying in some parts of the flow $\left(D_{b}>D_{b t}\right)$ and diminishing in other parts $\left(D_{b}<D_{b t}\right)$ the effect of turbulence. In extreme cases $D_{b}$ may even become negative (see [2] and [11]). Under such conditions, further where $D_{b}$ fluctuates strongly in the plane, the two-dimensional approach is obviously inapplicable. Similar experiences have been made during the investigations A3, and B3. One of the results obtained in the experiments in the strongly curved laboratory flume is shown in Fig. 11. Contrary to expectations, the peak velocities occurred along the inner, rather than the outer side of the curve. The secondary currents developing could clearly be traced by velocity component measurement and resulted, logically, in considerable transverse slopes. From the concentration distributions observed it will be appreciated in agreement with the results of Chang [2] that the edge of the plume separates from the wall, the line of peak concentrations approaching the center line of the flume. Assuming the validity of a Fick-type law, it is impossible to describe this behaviour in two dimensions. The dispersion coefficient varies depending on secondary flow, the average over the full stretch being $d \cong 0.35$ according to Eq. (17). Over the section $0-1$ its value is small $\left(\Delta \mathrm{D}_{\mathrm{b}}<0\right)$, increasing thereafter substantially (section $\left.1-3, \Delta \mathrm{D}_{\mathrm{b}} \gg \mathrm{D}_{\mathrm{bt}}, \mathrm{d} \cong 0.85\right)$, turning negative between 3 and $4\left(\Delta D_{b}<0,\left|\Delta D_{b}\right|>D_{b t}\right)$, assuming eventually again a positive value (d $\cong 0.060)$. Neither can the transverse changes be neglected. For instance, in cross-section 2, where a positive average was obtained by the method of moments, Eq. (18) yields $d \cong-0.08$ at $5 \mathrm{~cm}$ distance from the right-hand flume wall with the velocities, concentrations and pulsations measured.

In connection with the dispersion coefficients derived from the various tracer measurements, additional conclusions can be arrived at. Introducing also the results of the experiment B3. ( $\cong 1.6$ ), the dimensionsless dispersion coefficient related to width, $\mathrm{D}_{\mathrm{b}} / \mathrm{u} * \mathrm{~B}$, tends to decrease hyperbolically with increasing $\mathrm{B} / \mathrm{H}$ ratios, in agreement with the results of Lau and Krishnappen [8] obtained in straight, rectangular flumes. This suggests that the magnitude of $D_{b}$ is strongly affected through $\Delta D_{b}$ by the secondary currents. Moreover, from investigations on a small stream Muszkalay [9] has demonstrated that in the modified relationship obtained by introducing Nikuradse's roughness into the expression $D_{b}=d H^{*}$, the fluctuation of the resulting dimensionless dispersion coefficient is substantially reduced. This implies the role of friction. Using the available and future data it is, therefore, considered logical to attempt a description of $\mathrm{D}_{\mathrm{b}}$ by combining the parameters $\mathrm{D}_{\mathrm{bt}} / \mathrm{Hu}^{*}$ and $\Delta \mathrm{D}_{\mathrm{b}} / \mathrm{Bu}^{*}$, which can be correlated separately with different hydraulic and geometric quantities.

The elimination of both kinds of limitations mentioned in this section can be expected from adopting a three-dimensional approach which incorporates also an appropriate turbulence model.

\section{Conclusions}

Transverse mixing has been studied by introducing the concept and equations of mass streamline. Dye measurements were performed on several streams and the results compared to the calculated concentrations. The conclusions are as follows: i) The methods derived are well suited to calculating the concentration field and the transverse dispersion coefficient.

ii) In the absence of sudden changes in channel geometry, and of strong curvatures, there was satisfactory agreement between the calculated and observed values. However, the agreement depended in closeness on the accuracy of the velocity field and the dispersion coefficient involving aslo their spatial changes, especially if near bank discharges 


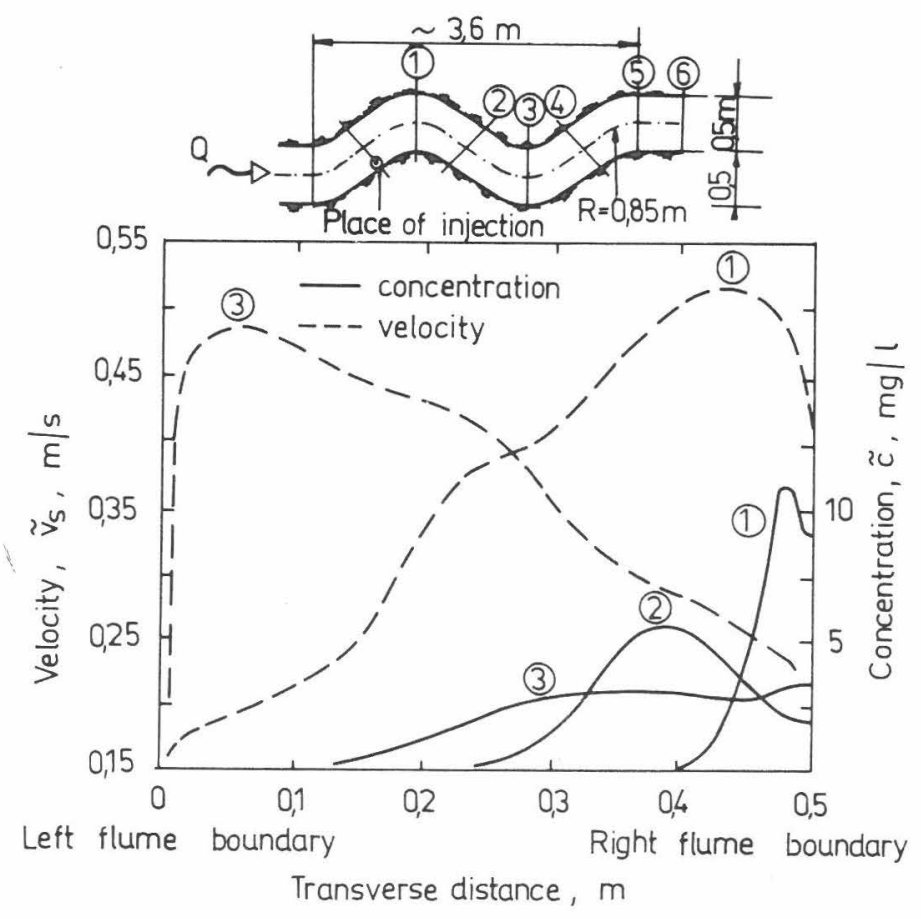

Measured concentrations and velocities. Curved laboratory flume

Fig. 11 Mesures de concentrations et de vitesses en laboratoire. Cas de méandres

were considered. Since no adequately supported method is thus far available for determining the velocity field and the variable dispersion coefficient, the dispersion model can be applied mainly for an overall description of the phenomenon.

iii) In the presence of sharp bends, expansions and concentrations, the effect of turbulence on mixing is amplified or diminished by the secondary currents developing. The dispersion coefficient fluctuates accordingly in both directions considerably, assuming potentially even negative values. In such cases the two-dimensional treatment cannot be successfully applied and a generalized, three-dimensional approach involving the equations of motion and continuity, further the turbulence model is alone likely to be suceessful.

iv) In the experiments on the various streams the ratio $\mathrm{B} / \mathrm{H}$ ranged from 3.5 to 100 . Values from 0.08 to 1.6 have been obtained for the dimensionless dispersion coefficient $\mathrm{D}_{\mathrm{b}} / \mathrm{u}^{*} \mathrm{H}$. It is suggested for the future to correlate $\mathrm{D}_{\mathrm{b}}$ with different geometric and hydraulic parameters to establish the contribution of friction and secondary currents, respectively. 
1. BANSAL, M.K., Dispersion in natural streams, Journal of the Hydraulics Division, ASCE, Vol. 97 No. HY1, Proc. Paper 8540, November 1971, pp. 1867-1886.

2. CHANG, Y.G., Lateral mixing in meandering channels, thesis presented in partial fulfillment of the requirements for the degree of Doctor of Philosophy, The University of Iowa, 1971 , p. 195.

3. FISCHER, H.B., The effect of bends on dispersion in streams, Water Resources Research, Vol. 5 No. 2, April 1969, pp. 496-506.

4. HOLLEY, E.R., Transverse mixing in rivers, Report of Delft Hydraulics Laboratory, S 132,1971 , p. 92 .

5. HOLLEY, E.R., SIEMONS, J. and G. ABRAHAM, Some aspects of analyzing transverse diffusion in rivers, Journal of Hydraulic Research 10 No. 1, 1972, pp. 27-57.

6. HOLLY, F.M., Jr., Two-dimensional mass dispersion in rivers, Hydrology Papers, Colorado State University, Fort Collins, Colorado, No. 78, 1975, p. 67.

7. KRISHNAPPEN, B.G. and L.Y. LAU, Transverse dispersion in meandering channels, Scientific Series No. 75, Inland Waters Directorate, Canada Centre for Inland Waters, Burlington, Ontario, 1977, p. 98.

8. LAU, L.Y. and B.G. KRISHNAPPEN, Transverse dispersion in rectangular channels, Journal of the Hydraulies Division, ASCE, Vol. 103 No. Hy 10, Proc. Paper 13294, October 1977 , pp. 1173-1189.

9. MUSZKALAY, L, Determination of the relationship between the turbulent dispersion coefficients and mixing lengths, (in Hungarian) VITUKI Report, I.2.4.1., 1978, pp. 56.

10. PAAL, L.L., VELNER, H.A., LIIV, U.R. and L.O. RODZILLER, The role of hydraulic factors in water quality control, Proc. of 15 th Congress of the IAHR, Istanbul, 1973, B2.

11. SAYRE, W.W., Natural mixing processes in rivers, in Environmental impact on rivers (River mechanics III), edited and published by Hsieh Wen Shen, Fort Collins, Colorado, 1973, Chapter 6.

12. SAYRE, W.W. and F.M. CHANG, A laboratory investigation of open-channel dispersion processes for dissolved, suspended and floating dispersants, U.S. Geological Survey Professional Paper 433-E, Government Printing Office, 1968, p. 71.

13. SOMLYÓDY,L., Examination of mixing in water streams using mass flux constant curves, Acta Technica, Tomus 82, (1-2), 1976, pp. 197-210.

14. SOMLYÓDY, L., Dispersion measurement on the Danube, Water Research, Vol. II, 1977, pp. 411-417.

15. SOMLYÓDY, L., Determination of the effluent mixing process in streams by introducing the mass streamline concept, (in Hongarian), Thesis presented for the degree of Candidate of Science, Hungarian Academy of Science, Budapest, 1978, pp. 150 .

16. SOMLYÓDY, L., Mixing model for large streams, Progress in Water Technology, Vol. 10 Nos. 5/6, pp. 97-104.

17. SOMLYÓDY, L., The use and limitations of two-dimensional mixing model for rivers, IAHS-AISH Publ. No. 125, 1978, pp. 96-105.

18. YOTSUKARA, N. and E.D. COBB, Transverse diffusion of solutes in natural streams, U.S. Geological Professional Paper 582-C, Government Printing Office, Washington, 1972, p. 19.

19. YOTSUKARA, N., FISCHER, H.B. and W.W. SAYRE, Mixing characteristics of the Missouri River between Sioux City, Iowa and Plattsmouth, Nebraska, Water Supply Paper 1899-G, U.S. Geological Survey, Government Printing Office, Washington, 1970 , p. 29.

20. YOTSUKARA, M. and W.W. SAYRE, Transverse mixing in natural channels, Water Resource Research, Vol. 12 No. 4, August 1976, pp. 695-704. 


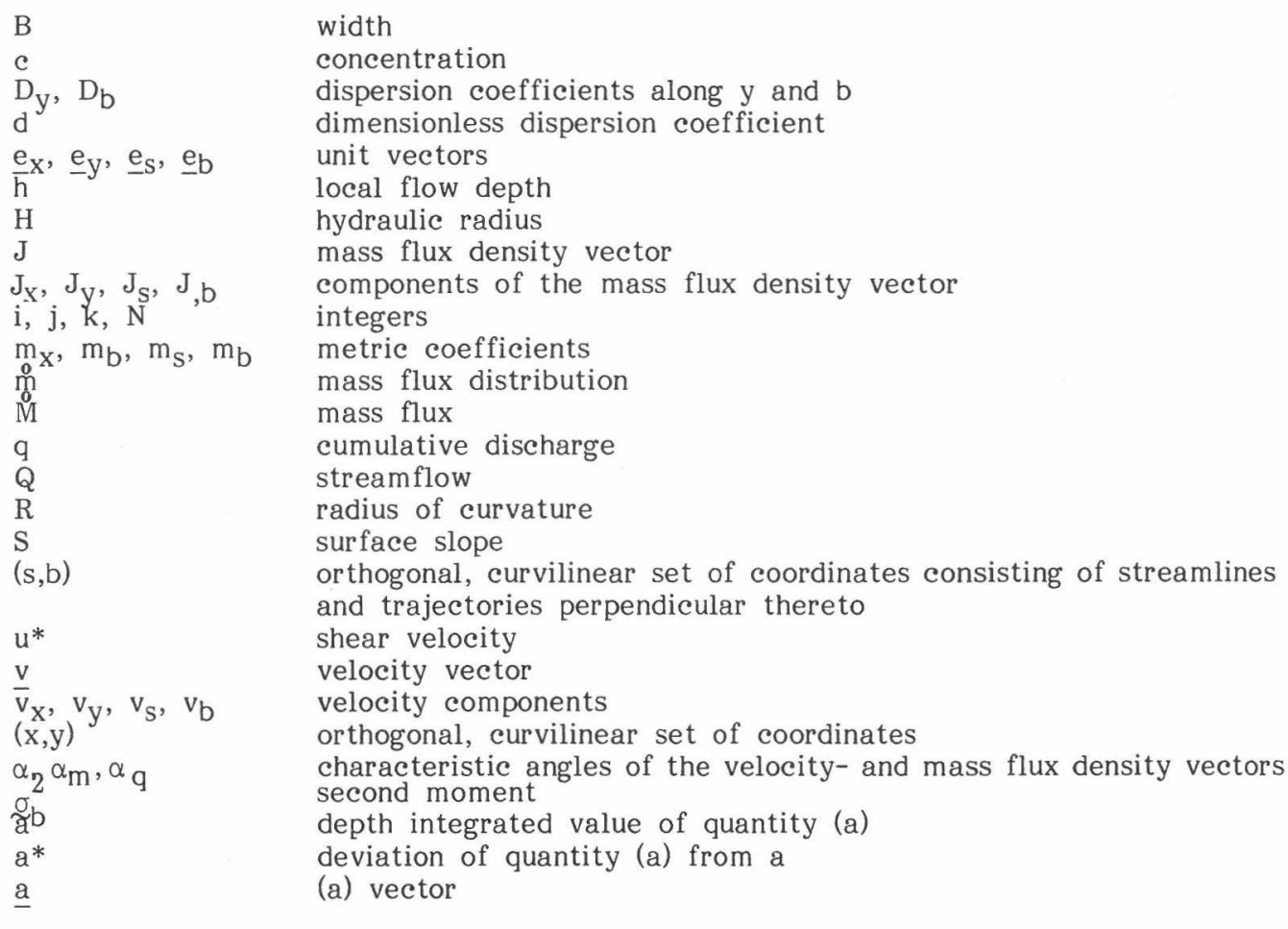


